\title{
3304 ディスクブレーキの鳴きに関する一考察
}

\section{Inquiry about Squeal of a Disk Brake}

\author{
○吉原 聖（東京農工大学） 正 鎌田崇義（東京農工大学） \\ 正 永井正夫（東京農工大学） 久米村洋一（トキコ株式会社）
}

\begin{abstract}
Satoshi YOSHIHARA, Takayoshi KAMADA，Masao NAGAI
Tokyo University of Agriculture and Technology, 2-24-16 Naka-cho, Koganei-city, Tokyo Yohichi KUMEMURA
\end{abstract}

TOKICO-Co., 1-6-3 Fujimi, Kawasaki-ku, Kawasaki-city, Kanagawa

This paper describes the numerical results about squeal of disk brake. The squeal considered in this paper is low frequency squeal $(1.8 \sim 2.5 \mathrm{kHz})$, and has coupled vibration modes between rotor and caliper through pads. To investigate the mechanism of low frequency squeal, disk brake is modeled as a two-degree-of-freedom model. The brake system become unstable and occur the squeal when the coefficient of friction is relatively high. And to make the stiffness of caliper bigger, the squeal is restrained.

From the analysis, it was made clear that the coefficient of friction between rotor and pads, and stiffness of caliper (especially the stiffness of trailing side) had grent influence to the low frequency squeal. So in design of the real brake system, these values are very important to restrain the low frequency squeal.

Key Words : Frictional Vibration, Self-Excited Vibration, Stability, Disk Brake, Squeal

\section{1. 緒 嘼}

現在, 自動車用ディスクブレーキにおいて要求されるのは, 制動性能はもちろん，制動時に発生するブレーキノイズを防 止して快適性の向上を図ることも重要な課題の一つとなって いる(1). ブレーキノイズとしては，ブレーキの鳴きやグロー ン音などが一般に知られているが，その中でもブレーキの鳴 きは, その周波数が数 $\mathrm{kHz}$ から 10 数 $\mathrm{kHz}$ に及び, 実際上最 も問題となりやすい(2).また，エンジンなどの騒音が低減さ れる一方で，鳴きは相対的に大きな騒音源となっており，と りわけ高級車には極めて頭の痛い問題である. その対策とし て，実機においては剛性を上げることで鳴きを抑えるといっ たことが行われており，一定の効果を上げている(3).しかし， 理論的な立場からは,ブレ一キの鳴きは古くから研究されて いたにも関わらず，いまだに根本的な解決に至っていないの が実状である.

従来の自動車用ディスクブレーキの鳴きは, ロータとパッ ドとの摩擦による連成振動で，キャリパはあまり振動しない
タイプのものであった. しかし，ディスクブレーキが大型化 するにつれて，ロータとキャリパがパッドを介して連成振動 するタイプの鳴きがしばしば生じてきている，その周波数も 従来のおよそ $5 \mathrm{kHz}$ 以上の高周波鳴きから， $1.8 \sim 2.5 \mathrm{kHz}$ の 低周波鳴きへと変化している(4).

ブレーキの鳴きは, パッドとロータとの摩擦により発生す る摩擦振動に起因し, 特にパッドが接触, 非接触のサイクル を綝り返すときに発生する．多くは摩擦振動がブレーキ構造 体に伝達され, 部材の共振などによる増幅作用を受けて大き な音になることから，摩擦振動とその増幅作用が主な要因で ある。

そこで本研究では, 摩擦振動発生のメカニズムを知るため に, 簡単な 2 自由度系に対して理論的な検討を行う.とくに, 摩擦係数と接触剛性に注目して, ディスクブレーキの鳴きと 摩擦振動発生のメカニズムとの関係を調べる.

\section{2. 解析モテル}


図 1 に示すような剛体ブロック系を対象にして分布する摩 擦によって起こされる摩擦振動を解析する.この解析モデル とディスクブレーキの対応を考えると，キャリアを 2 つのば ねで支持された剛体ブロックとして車体側（inner 側）のみ を考應し，ロータは振動しない用体と見なし，パッドを接触 ばねでモデル化していることに相当する．なお，ロータが回 転してキャリアに入ってくる側を leading 側, 出てくる側を trailing 側と呼ぶ. 自由度は, 垂直方向と回転方向の 2 自由 度としている。

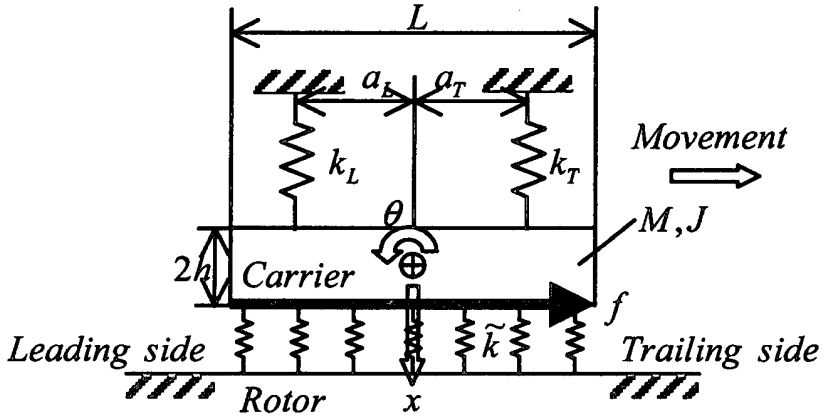

Fig.1 Analytical model

\section{1 毁号の定军}

表1に解析モデルに用いた記号の定義を示す。

Table1 Characteristics of analytical model

$\begin{array}{ll}M & \text { キャリアの質量 } \\ J & \text { キャリアの重心回りの慣性モーメント } \\ L & \text { キャリアの幅 } \\ h & \text { キャリアの厚み } \\ a_{L} & \text { キャリアの重心と leading 側支持ばねとの距離 } \\ a_{T} & \text { キャリアの重心と trailing 側支持ばねとの距離 } \\ k_{L} & \text { leading 側支持ばね } \\ k_{T} & \text { trailing 側支持ばね } \\ \tilde{k} & \text { 分布接触ばね } \\ \mu & \text { 摩擦係数 } \\ f & \text { 摩擦力 }\end{array}$

\section{2 動方程式}

ブロックの垂直方向変位 $x$ および重心回りの回転角 $\theta$ に関 する運動方程式を（1）に示す.

$$
\mathbf{M} \ddot{\mathbf{X}}+\mathbf{K} \mathbf{X}=\mathbf{0}
$$

ここに， $\mathrm{X}=(x, \theta)^{T}$ ，有号 $T$ は転置記号であり，

$$
\begin{aligned}
& \mathbf{M}=\left[\begin{array}{cc}
M & 0 \\
0 & J
\end{array}\right], \quad \mathbf{K}=\left[\begin{array}{ll}
k_{11} & k_{12} \\
k_{21} & k_{22}
\end{array}\right] \\
& k_{11}=k_{L}+k_{T}+\tilde{k} L \\
& k_{12}=a_{L} k_{L}-a_{T} k_{T} \\
& k_{21}=a_{L} k_{L}-a_{T} k_{T}-\mu \tilde{k} h L \\
& k_{22}=a_{L}{ }^{2} k_{L}+a_{T}{ }^{2} k_{T}+\tilde{k} L^{3} / 12
\end{aligned}
$$

と表される。

運動方程式（1）において，剛性行列が摩擦のために非対称 性を有する．これが，摩擦による不安定振動の原因である. 式 (1) の固有值解析から, 安定性が判別される ${ }^{(5)}$. すなわち, 特性方程式の根に 1 つでも実部が正の根が存在すると不安定, すなわち, 摩擦振動が発生する. 式 (2) に特性方程式を示す.

$$
M J \lambda^{4}+\left(k_{11} J+k_{22} M\right) \lambda^{2}+\left(k_{11} k_{22}-k_{12} k_{21}\right)=0
$$

今回は図 1 に示す解析モデルにおいて，どのような条件の ときに不安定系になるかを搩り,シミュレーションを行った．

\section{3. シミュレーション結果及び考察}

シミュレーション条件においては，キャリアの重心に変位 $x=1.0 \times 10^{-7}$ を下向きに与え, このときの垂直方向加速度, 回転方向加速度の時系列応答を見る．また，シミュレーショ ンで使用したパラメータの值を表 2 に示す. 本モデルのパラ メータは，低周波鳴き $2 \mathrm{kHz}$ を対象として設定した值である。 ここでは, 今回行った（1）摩擦係数を変化させた場合，(2) $k_{r}$ を変化させた場合の結果について示す.

Table2 Value of parameters

\begin{tabular}{c|c|c|c}
\hline$M$ & $2.2 \mathrm{~kg}$ & $a_{L}$ & $2.13 \times 10^{-2} \mathrm{~m}$ \\
\hline$J$ & $2.64 \times 10^{-3} \mathrm{kgm}^{2}$ & $a_{T}$ & $2.13 \times 10^{-2} \mathrm{~m}$ \\
\hline$L$ & $0.12 \mathrm{~m}$ & $k_{L}$ & $4.26 \times 10^{7} \mathrm{~N} / \mathrm{m}$ \\
\hline$h$ & $0.015 \mathrm{~m}$ & $k_{T}$ & $2.50 \times 10^{7} \mathrm{~N} / \mathrm{m}$ \\
\hline$\tilde{k}$ & $2.55 \times 10^{9} \mathrm{~N} / \mathrm{m}^{2}$ & \multicolumn{2}{|c}{} \\
\hline
\end{tabular}

\section{（1）摩撩係数を変化させた場合}

まず，摩擦係数 $\mu$ をいろいろと変化させていき，安定性の 影響についてシミュレーションを行った. $\mu=0.38$ のときの 時系列応答を図 2 に, $\mu=0.39$ のときの時系列応答を図 3 に 示す. 図 2，3の（a）（b）はそれぞれ垂直方向加速度，回転 方向加速度を表す.すると，摩擦係数 $\mu=0.38, \mu=0.39$ を境 に安定，不安定となることが分かった。この現象が，構造的 


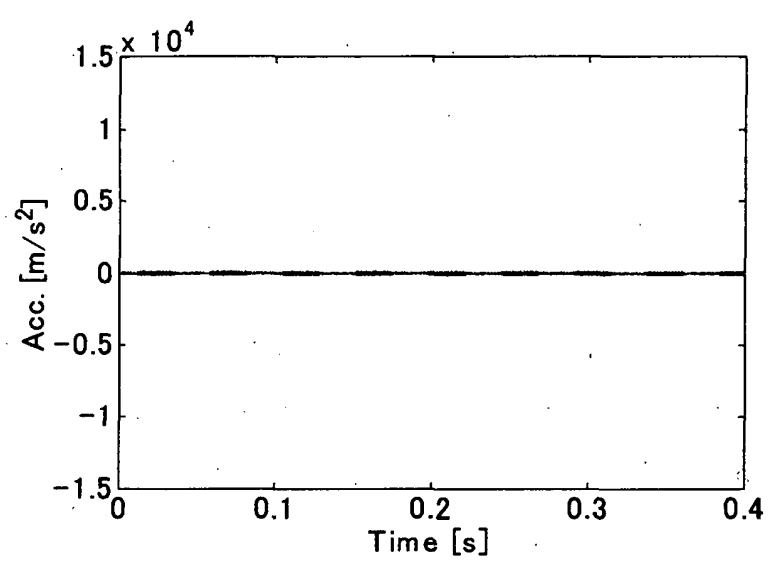

(a) Vertical acceleration

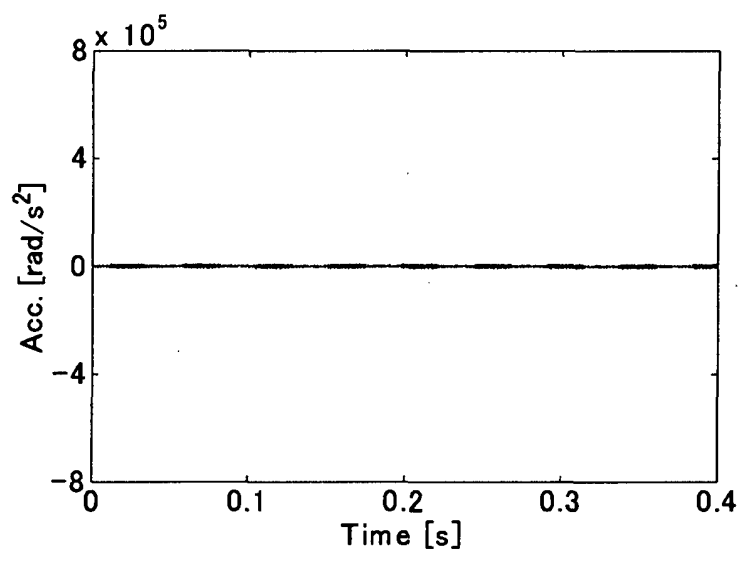

(b) Rotational acceleration

Fig.2 Time series response $(\mu=0.38)$

にどのようになっているのか知るために, 前章で述べた式 (2) を念頭におきながら, 特性根, 剛性行列の非対角項について 調べ，安定性を判別した。

摩擦係数 $\mu=0.38, \mu=0.39$ のときの用性行列の非対角項の 值 $k_{12} ， k_{21}$ および特性根 $\lambda$ を表 3 にまとめた． $\lambda$ に関して, $\mu=0.39$ のときに実部が正の根が存在することが分かった. このことにより系が不安定，つまり摩擦振動が発生している ことが確認できた. また $k_{12}, k_{21}$ の值に関して調べてみると， どちらの摩擦係数においても $k_{12}, k_{21}$ の符号が負であること が分かった。このことにより，構造的に摩擦振動を生じるた めには，特性根の実部が大きく関わることが分かった。

\section{（2） $k_{r}$ を交化させた塄合}

次に, trailing 側支持ばね $k_{T}$ をいろいろと変化させていっ たときの安定性の影響について, 摩擦係数を一定にこでは, $\mu=0.39)$ としてシミュレーションを行った. $k_{T}=2.51 \times$ $10^{7} \mathrm{~N} / \mathrm{m}$ のときの時系列忘答を図 4 に示す. 図 4 においても （a），(b) はそれぞれ垂直方向加速度，回転方向加速度を示

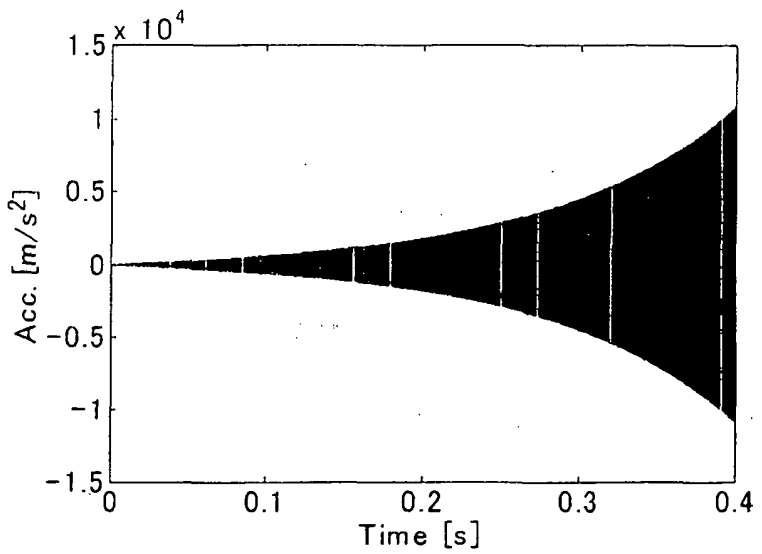

(a) Vertical acceleration

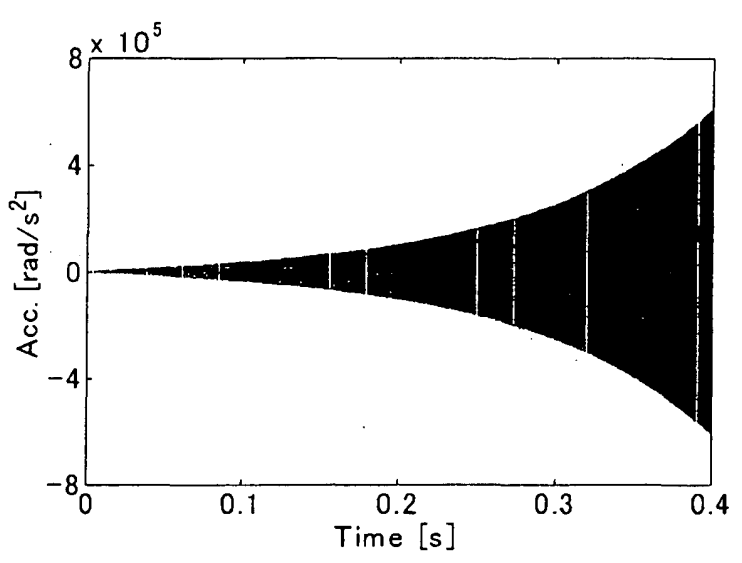

(b) Rotational acceleration

Fig.3 Time series response $(\mu=0.39)$

Table3 Numerical computational results

\begin{tabular}{|c|c|c|c|}
\hline$\mu$ & $k_{12}$ & $k_{21}$ & $\lambda$ \\
\hline 0.38 & 374880 & -1369620 & $\begin{array}{l} \pm 1.26 \times 10^{4} i \\
\pm 1.27 \times 10^{4} i\end{array}$ \\
\hline 0.39 & 374880 & -1415220 & $\begin{array}{r}8.6 \pm 1.27 \times 10^{4} i \\
-8.6 \pm 1.27 \times 10^{4} i\end{array}$ \\
\hline
\end{tabular}

す.すると $k_{T}=2.5 \times 10^{7} \mathrm{~N} / \mathrm{m}, k_{T}=2.51 \times 10^{7} \mathrm{~N} / \mathrm{m}$ を境に安 定，不安定になることが分かった。このことから，前節の結 果と比較して，摩擦倸数がある值を境に発振していた場合で も， $k_{T}$ を変えることで，つまり用性を変えることで発振現象 が変わることが分かった．次に前節同様，特性根，剛性行列 の非対角項についても調べ，安定性を判別した． $k_{T}=2.5 \times$ $10^{7} \mathrm{~N} / \mathrm{m}, k_{T}=2.51 \times 10^{7} \mathrm{~N} / \mathrm{m}$ のときの剛性行列の非対角項の 值 $k_{12} ， k_{21}$ および特性根 $\lambda$ を表 4 にまとめた． $\lambda$ に関して, 


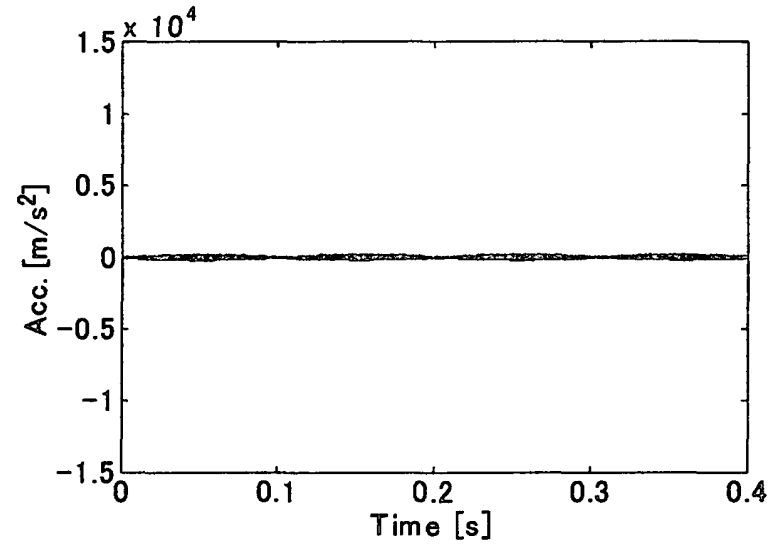

(a) Vertical acceleration

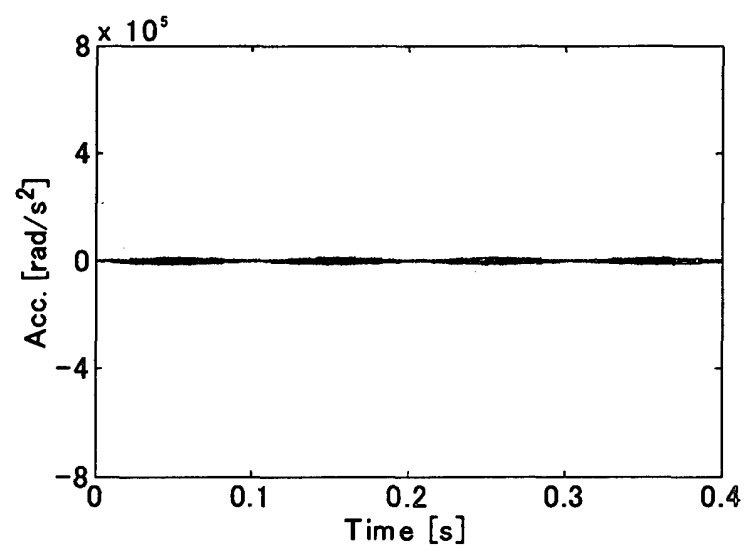

(b) Rotational acceleration

Fig. 4 Time series response $\left(k_{T}=2.51 \times 10^{7} \mathrm{~N} / \mathrm{m}\right)$

Table4 Numerical computational results

\begin{tabular}{|c|c|c|c|}
\hline$k_{T}$ & $k_{12}$ & $k_{21}$ & $\lambda$ \\
\hline $2.5 \times 10^{7}$ & 374880 & -1415220 & $\begin{array}{c}8.6 \pm 1.27 \times 10^{4} i \\
-8.6 \pm 1.27 \times 10^{4} i\end{array}$ \\
\hline \multirow{2}{*}{$2.51 \times 10^{7}$} & 372750 & -1417350 & $\begin{array}{l} \pm 1.26 \times 10^{4} i \\
\pm 1.27 \times 10^{4} i\end{array}$ \\
\hline
\end{tabular}

$k_{T}=2.5 \times 10^{7} \mathrm{~N} / \mathrm{m}$ のときに実部が正の根が存在することが分 かり，系が不安定であることから，摩擦振動が発生している ことが確認できた. また，剛性行列の非対角項の值 $k_{12}, k_{21}$ に 関して調べてみると，前節同様どちらにおいても $k_{12}, k_{21}$ の 符号が負であることが分かった。

\section{4. 結 佥}

本研究より得られた結果は, 以下のようにまとめられる.
（1）摩擦係数のある值を境に，系が不安定になり，摩攃振動 が起こることが確認できた。

（2）摩擦振動を発生させるには, 特性方程式の根に 1 つでも 実部が正の根が存在すれば，系が不安定になることが確認で きた.

（3） trailing 側支持ばね $k_{T}$ の值によって，鳴きの発生状況 が変化することが分かった，今回の結果からは，摩擦係数を 不安定になるときにした場合でも，ある值を境に系が安定， 不安定になり，摩擦振動が起こることが分かった．つまり， trailing 側支持ばね $k_{T}$ の大きさが, 摩擦振動の発生に影響し ていると言える.このことは, ディスクブレーキの鳴き防止 設計に，重要な指針を与えると考えられる.

\section{文 献}

（1）自動車工学全書編集委員会, 自動車工学全書 全 26 冊 (12 巻 タイヤ, ブレーキ), 1980, 145-146, 山海堂.

（2）原田 宏 - 岡村廣正 - 西脇正明 - 池内孝広，ブレーキ， イズに関する研究（第 2 報, ディスクブレーキの鳴きの 場合)，機論，55-512，C (1989)，932-939.

（3）脇 和文，ブレ一キの鳴きに関する研究（ブレーキ各部 の剛性の影響について), 1999, 1-8.

（4）末岡淳男・劉 孝宏・白水健次・市場保昭, 自動車用フ ローティング型ディスクブレ一キの鳴き（第 1 報, 鳴き 発生とパッド/ロータ間の接触位㯰関係の赛験), 機論, 67-658, C (2001), 1719-1726.

（5）末岡潡男 - 金光陽一。近藤孝広, 機械振動学, (2000), 173-180，朝倉書店. 